University of Nebraska - Lincoln

DigitalCommons@University of Nebraska - Lincoln

$8-2-2000$

\title{
Social Anxiety Scale for Adolescents: Normative Data and Further Evidence of Construct Validity
}

Heidi M. Inderbitzen-Nolan

University of Nebraska-Lincoln

Kenneth S. Walters

University of Nebraska-Lincoln, waltersk4@southernct.edu

Follow this and additional works at: https://digitalcommons.unl.edu/psychfacpub

Part of the Psychiatry and Psychology Commons

Inderbitzen-Nolan, Heidi M. and Walters, Kenneth S., "Social Anxiety Scale for Adolescents: Normative Data and Further Evidence of Construct Validity" (2000). Faculty Publications, Department of Psychology. 311.

https://digitalcommons.unl.edu/psychfacpub/311

This Article is brought to you for free and open access by the Psychology, Department of at DigitalCommons@University of Nebraska - Lincoln. It has been accepted for inclusion in Faculty Publications, Department of Psychology by an authorized administrator of DigitalCommons@University of Nebraska - Lincoln. 


\title{
Social Anxiety Scale for Adolescents: Normative Data and Further Evidence of Construct Validity
}

\author{
Heidi M. Inderbitzen-Nolan and Kenneth S. Walters \\ Department of Psychology, University of Nebraska-Lincoln
}

\begin{abstract}
Replicates and extends prior work with the Social Anxiety Scale for Adolescents (SASA) by providing psychometric data, further evidence of construct validity, and largesample based normative data. Participants were 2,937 students (1,431 boys and 1,506 girls) in Grades 6, 7, 8, 9, and 11. Students completed the SAS-A, the Revised Children's Manifest Anxiety Scale (RCMAS), and the Children's Depression Inventory $(C D I)$. Results replicated a three-factor structure for the $S A S-A$, with good internal consistencies for its subscales. Normative data were subdivided by sex and grade group. Construct validity included replication of prior relations with general anxiety (RCMAS) and depressive symptomatology (CDI). Implications of these results for further use and norming of the $S A S-A$ are discussed.
\end{abstract}

Although social phobia (or social anxiety disorder) has been the focus of increased research attention in recent years, such research has concentrated primarily on adult populations (Beidel \& Randall, 1994). Yet, social phobia is believed to affect significant numbers of children and adolescents. Studies have reported youth rates from $1.1 \%$ to $3.7 \%$ in the general population (Benjamin, Costello, \& Warren, 1990; Verhulst, van der Ende, Ferdinand, \& Kasius, 1997) and from 14.9\% to $30 \%$ in clinical populations (Last, Perrin, Hersen, \& Kazdin, 1992; Strauss \& Last, 1993).

Additionally, social phobia is associated with significant impairment in functioning for youths. Social phobia in adolescence is likely to interfere with normal development of social and personal relationships (Ballenger et al., 1998) and result in school avoidance or refusal (Strauss \& Francis, 1989). Socially phobic adolescents also report experiencing significant degrees of depression and suicidal ideation (Francis, Last, $\&$ Strauss, 1992) and are at risk for substance abuse problems (Clark, 1993). Furthermore, social phobia in youths has been associated with increased rates of conduct problems such as being truant, running away from home, fighting, and telling lies (Davidson, Hughes, George, \& Blazer, 1993).

Although social phobia is believed to affect numerous youths and to result in serious consequences, the study of social phobia and social anxiety in youths is

Completion of this project was made possible by support from $\mathrm{Na}$ tional Institutes of Mental Health Grant 5R03MHS263802 awarded to Heidi M. Inderbitzen-Nolan.

Requests for reprints should be sent to Heidi M. InderbitzenNolan, University of Nebraska-Lincoln, Department of Psychology, 238 Burnett Hall, Lincoln, NE 68588-0308. just beginning. One reason for this apparent slow start, in comparison with research with adults, was the absence of a psychometrically sound measure for assessing social anxiety in children and adolescents ( $\mathrm{La}$ Greca, 1998). In 1988, however, La Greca, Dandes, Wick, Shaw, and Stone developed the first paper-andpencil measure of social anxiety for children: the Social Anxiety Scale for Children (SASC).

The SASC consisted of 10 items and, based on Watson and Friend's (1969) Social Avoidance and Distress scale (SAD), was designed to assess two distinct underlying constructs: social avoidance and distress and fear of negative evaluation. Factor analysis of the 10-item scale yielded two primary factors: one assessing fear of negative evaluation by peers (FNE) and one assessing children's social avoidance and distress (SAD).

Research with the SASC (La Greca et al., 1988) indicated that the scale had acceptable internal consistencies and test-retest reliability over a 2 -week period for both subscales. The authors realized, however, that the items on the SAD were fairly circumscribed and the test-retest reliability was somewhat lower for the SAD subscale compared with the FNE subscale. Thus, in an attempt to improve the reliability and the content of the SAD subscale, new items were added, resulting in the Social Anxiety Scale for Children-Revised (SASC-R).

The SASC-R consists of 22 items: 18 content items and 4 filler items. Investigation of the psychometric properties of the SASC-R (La Greca \& Stone, 1993) yielded three factors: Fear of Negative Evaluation (FNE), which consists of eight items assessing children's fears, concerns, or worries regarding peers' negative evaluations; Social Avoidance and Distress in New Situations (SAD-New), which consists of six items assessing children's social avoidance and distress with new social situations or with unfamiliar 
peers; and Social Avoidance and Distress-General (SAD-General), which consists of four items assessing general social inhibition, distress, and discomfort. La Greca (1998) reported that the three-factor model of the SASC-R fit the data better than the original two-factor model, and thus the three-factor model has been retained.

Additional psychometric investigation of the SASC-R has yielded good internal consistencies for community and clinical samples (.60 to .90; Ginsberg, La Grecca, \& Silverman, 1998; La Greca \& Stone, 1993) and significant test-retest reliabilities (.36 to .42 over a 1-year period). Construct validity for the SASC$\mathrm{R}$ has been demonstrated in several different studies. La Greca and Stone (1993) found that children who reported higher levels of social anxiety on the SASC-R also reported perceiving themselves as being less accepted and as having less self-worth. In another study, Ginsburg et al. (1998) found that in a sample of children with a primary diagnosis of simple phobia, those who had comorbid socially based anxiety disorders (e.g., social phobia, avoidant disorder, or overanxious disorder) scored higher on the SASC-R than did those without such comorbid diagnoses.

To be useful for adolescent populations, the items on the SASC-R were modified somewhat to form the Social Anxiety Scale for Adolescents (SAS-A; La Greca \& Lopez, 1998). With regard to the number of items, the content of items, and the 5-point rating scale format, the SAS-A is identical to the SASC-R. The wording of some of the items, however, was changed to make it more appropriate for adolescents. For example, other kids was changed to peers or others, and playing was changed to doing things.

Although not as extensive as for the SASC-R, psychometric data on the SAS-A exist. Using both adolescent community and clinical populations, researchers have replicated the three-factor structure of the SASC-R and reported good internal consistencies (ranging from .76 to .91; Ginsburg, La Greca, \& Silverman, 1997; La Greca \& Lopez, 1998). Furthermore, test-retest reliabilities range from .54 to .78 for a 2-month interval (La Greca, 1998) and from .47 to .75 for a 6-month interval (Vernberg, Abwender, Ewell, \& Beery, 1992).

Some concurrent validity data with regard to the SAS-A also exist. Similar to results with the SASC-R and children, La Greca and Lopez (1998) found that adolescents who scored higher on the SAS-A also reported lower self-perceptions of peer acceptance and romantic appeal. In addition, Inderbitzen, Walters, and Bukowski (1997) found that adolescents classified as rejected and neglected reported higher levels of social anxiety than did those classified as average, popular, or controversial. Finally, Ginsburg et al. (1997) found that adolescents with a primary diagnosis of social phobia had higher scores on the SAS-A than did adolescents with other anxiety disorders.

The purpose of this study was to replicate and extend previous research with the SAS-A. First, we sought to confirm the three-factor structure found in previous studies by using a larger adolescent sample. Second, this study was designed to provide a broader set of normative data by including a larger number of adolescents, adolescents from a wider range of socioeconomic status levels than in previous research, and adolescents in both junior high and high school. Third, we sought to provide additional construct validity for the SAS-A by investigating the relation between the SAS-A and the Revised Children's Manifest Anxiety Scale (RCMAS; a measure of unspecified or general anxiety) and the Children's Depression Inventory (CDI; a measure of depressive symptomatology).

\section{Method}

\section{Participants}

We recruited 2,937 students $(1,431$ boys and 1,506 girls) in Grades 6 (472; 226 boys and 246 girls), 7 (646; 320 boys and 326 girls), 8 (678; 324 boys and 354 girls), 9 (579; 282 boys and 297 girls), and 11 (562; 279 boys and 283 girls) from public and private schools in a midsized Midwestern city. Only students with parental consent and who signed assent forms were eligible for participation. Ethnicity data was obtained from 2,304 participants. ${ }^{1}$ Eighty-five percent of the youths who provided ethnicity data identified themselves as Caucasian, whereas the remaining $15 \%$ identified themselves as ethnic minorities (4.2\% African American, 3.5\% Mexican American, 2.8\% Asian American, 1.6\% Native American, and $2.9 \%$ biracial). Socioeconomic data, obtained from 1,840 participants, revealed that the adolescents came from a wide range of socioeconomic levels (9.9\% upper middle class, $18.6 \%$ middle class, $23.1 \%$ white collar professionals, $11.1 \%$ working class skilled laborers, $36.3 \%$ working class unskilled laborers, and 1\% impoverished).

\section{Measures}

As part of a larger project investigating familial and developmental correlates of social anxiety, students completed four measures relevant to the goals of this study.

${ }^{1}$ Some principals in participating schools did not allow students to complete the demographic questionnaire or some items on the demographic questionnaire (which was used to gather information concerning ethnicity and socioeconomic status). 
Demographic questionnaire. The demographic questionnaire was used to collect data regarding the youths' sex, age, ethnicity, socioeconomic status, and living situation. Students were also asked with whom they lived and the occupations of the adults with whom they resided so we could determine the family's socioeconomic status by using the Duncan Index (Reiss, 1961).

SAS-A. The SAS-A (La Greca, 1998) consists of 22 items divided into three subscales (FNE, eight items; SAD-New, six items; SAD-General, four items) and four filler items. Youths indicate on a 5point continuum how much each item characterizes themselves. Each subscale is scored in such a way that high scores reflect greater social anxiety. Scores from the three subscales are summed to form a total score.

RCMAS. The RCMAS (Reynolds \& Richmond, 1978) is a 37-item questionnaire used to assess anxiety symptoms in children and adolescents ages 6 through 19. The questionnaire consists of 28 items pertaining to subjective, physiological, and motoric indexes of anxiety that can be summed to form a total general anxiety score. These 28 items can also be divided into the following subscales: Physiological Anxiety, Worry/ Oversensitivity, and Social Concerns/Concentration. The remaining 9 items form a Lie scale, which can be used to assess youth's tendency to present themselves favorably. Reynolds and Richmond (1985) reported internal consistency coefficients ranging from .56 to .80 across 11 age groups for the three subscales and .80 for the total score.

CDI. The CDI (Kovacs \& Beck, 1977) is a 27item questionnaire that asks respondents to endorse statements reflecting cognitive and somatic symptoms of depression. The CDI was designed to be used with children and adolescents from 7 to 17 years of age. The measure consists of a total score and five subscales: Negative Mood, Interpersonal Problems, Ineffectiveness, Anhedonia, and Negative Self-Esteem. The CDI has been shown to have adequate internal consistency, with alpha coefficients ranging from .71 to .94 (Saylor, Finch, Spirito, \& Bennett, 1984) and to differentiate between children diagnosed as depressed and nondepressed (Carlson \& Cantwell, 1979).

\section{Procedure}

Letters describing the study were mailed to the homes of parents who had children enrolled in the target grades at participating schools. The specific method used to obtain parental consent varied across schools, depending on principals' preferences. In some schools, passive consent procedures were used, in which the let- ters mailed to the homes asked parents to call the primary investigator only if they did not wish their child to participate in the study. In other schools, active consent procedures were used, where parents were required to send a signed consent form back to school with their child. Parental consent rate averaged across schools using passive consent procedures was $96 \%$. Parental consent rate averaged across schools using active consent procedures was approximately $34 \% .^{2}$

Students with parental consent were asked to sign an assent form before completing any questionnaires. Only those students who did so were allowed to participate in the study. Assenting students completed the questionnaires at their own pace after receiving instructions as a group. Trained graduate and undergraduate assistants were available throughout the testing to answer questions or provide help as needed. Completion of questionnaires specific to this study took about $30 \mathrm{~min}$.

\section{Results}

\section{Data Analytic Strategy}

Participants were placed into one of the following two grade groups: junior high (i.e., Grades 6, 7, and 8) and senior high (i.e., Grades 9 and 11). ${ }^{3}$ Grade group was combined with sex to produce a $2 \times 2$ design for most analyses that follow.

Because of the large number of analyses performed and the potential for large sample sizes to result in minuscule differences being reported as statistically significant, we selected a conservative significance level for all between-group and correlational analyses. Thus, to reduce alpha-inflation and to focus on potentially meaningful results, only differences significant at $p<$ .001 are reported.

\section{Preliminary Analyses}

Because of large variability in socioeconomic status (SES) levels represented in this population, we examined the relation between SES and SAS-A scores. We conducted a series of between-group analyses of variance (ANOVAs) using SES group (e.g., upper middle class, middle class, etc. $)^{4}$ as the independent variable and SAS-A total scores, FNE, SAD-New, and SAD-

\footnotetext{
2Statistical analyses indicated no differences between students recruited using passive consent procedures and those using active consent procedures on any measures in this study.

${ }^{3}$ Initial exploratory analyses indicated that only minuscule differences existed among separate grades on all dependent measures in the study. Thus, we decided to group students into two larger grade groups.

4The impoverished group was omitted from the analyses because it contained only 13 participants.
} 
General subscale scores as dependent variables, respectively. There were no significant differences among the SES groups on any of the SAS-A scores, with effect sizes ranging from $\eta^{2}=.006$ to .003 . Additionally, two chi-square analyses were conducted to ensure that SES was evenly distributed across sex and grade groups. Both of these analyses were nonsignificant: for sex by SES, $\chi^{2}(4, N=1,840)=2.28, p=.80$; for grade group by SES, $\chi^{2}(4, \mathrm{~N}=1,840)=3.69, p=.59$.

\section{Psychometric Analysis of the SAS-A}

Confirmatory factor analyses were conducted on the items of the SAS-A to confirm the three-factor structure presented for adolescents by La Greca and Lopez
(1998). These analyses were performed for the total sample and by sex and grade group. The four filler items on the SAS-A were not included in these analyses. The remaining 18 items were loaded onto their respective factors (i.e., FNE, SAD-New, and SADGeneral) as presented in La Greca and Lopez. As can be seen in Table 1, loadings were generally consistent across the four subsamples and replicated those reported by La Greca and Lopez. Furthermore, as can be seen in Table 2, the fit indexes for the confirmatory factor analyses indicated that the three-factor model fit the data for the total sample and for all four subsamples.

Table 3 presents alpha coefficients and interscale correlations for the total sample as well as for sex and grade groups for the three subscales. Internal consistencies were high for all three subscales and highly consis-

Table 1. Factor Loadings From Confirmatory Factor Analyses on Social Anxiety Scale for Adolescents Items by Sex and Grade Group

\begin{tabular}{|c|c|c|c|c|c|}
\hline \multirow[b]{3}{*}{ Item } & \multicolumn{4}{|c|}{ Item Loading } & \multirow[b]{3}{*}{ Total } \\
\hline & \multicolumn{2}{|c|}{$\begin{array}{c}\text { Junior High } \\
\text { School }\end{array}$} & \multicolumn{2}{|c|}{$\begin{array}{c}\text { Senior High } \\
\text { School }\end{array}$} & \\
\hline & Boys & Girls & Boys & Girls & \\
\hline \multicolumn{6}{|l|}{ Fear of Negative Evaluation } \\
\hline I'm afraid that others will not like me. (9) & .95 & .98 & .87 & .91 & .95 \\
\hline I worry about what others think of me. (8) & .95 & .98 & .86 & .87 & .94 \\
\hline I worry what others say about me. (12) & .90 & .96 & .80 & .90 & .92 \\
\hline I worry that others don't like me. (14) & .93 & .93 & .77 & .90 & .90 \\
\hline I worry about being teased. (3) & .83 & .79 & .71 & .67 & .78 \\
\hline I feel that others are making fun of me. (17) & .78 & .77 & .57 & .56 & .70 \\
\hline I feel that peers talk about me behind my back. (6) & .63 & .73 & .48 & .53 & .62 \\
\hline If I get into an argument, I worry that the other person will not like me. (18) & .59 & .66 & .54 & .53 & .62 \\
\hline \multicolumn{6}{|l|}{ Social Avoidance and Distress-New } \\
\hline I get nervous when I talk to peers I don't know very well. (10) & .81 & .82 & .80 & .88 & .82 \\
\hline I feel shy around people I don't know. (4) & .72 & .79 & .70 & .79 & .76 \\
\hline I get nervous when I meet new people. (13) & .83 & .76 & .73 & .78 & .78 \\
\hline I feel nervous when I'm around certain people. (20) & .65 & .66 & .60 & .64 & .64 \\
\hline I worry about doing something new in front of others. (1) & .53 & .56 & .56 & .56 & .56 \\
\hline I only talk to people I know really well. (5) & .54 & .54 & 62 & .56 & .56 \\
\hline \multicolumn{6}{|l|}{ Social Avoidance and Distress-General } \\
\hline It's hard for me to ask others to do things with me. (22) & .83 & .73 & .76 & .80 & .78 \\
\hline I'm afraid to invite others to do things with me because they mightsay no. (19) & 69 & .71 & .71 & .71 & .71 \\
\hline I am quiet when I'm with a group of people. (15) & .48 & .59 & 62 & .59 & .56 \\
\hline I feel shy even with peers I know very well. (21) & .53 & .51 & .48 & .57 & .52 \\
\hline
\end{tabular}

Note: Item numbers are in parentheses. Item loadings represent loadings for specific items onto the factor for which that item was assigned based on La Greca and Lopez (1998).

Table 2. Results of Confirmatory Factory Analyses on Social Anxiety Scale for Adolescents Items by Sex and Grade Group

\begin{tabular}{lcccc}
\hline Group/Model & $\boldsymbol{n}$ & $\chi^{\mathbf{2}}$ & GFI & CFI \\
\hline Junior High School & & & & .94 \\
$\quad$ Boys & 870 & 482.54 & .93 & .94 \\
$\quad$ Girls & 926 & 592.02 & & .94 \\
Senior High School & & & .91 & .92 \\
$\quad$ Boys & 561 & 471.69 & .88 & .90 \\
$\quad$ Girls & 580 & 1551.83 & .94 & .94 \\
Total & 2937 & & \\
\hline
\end{tabular}

Note: $\mathrm{GFI}=$ goodness of fit index; $\mathrm{CFI}=$ comparative fit index. All chi-square tests have 132 degrees of freedom and are significant at $p<.001$. 
tent across the four subsamples. The interscale correlations were also consistent across subsamples and suggest that the subscales of the SAS-A represent interrelated but distinct subconstructs of social anxiety. Both the internal consistencies and the interscale correlations were comparable to prior work with the SAS-A (La Greca, 1998).

\section{Sex and Grade Group Differences}

Sex and grade group differences on the SAS-A. We calculated a $2 \times 2$ (Sex $\times$ Grade Group) betweengroup ANOVA using the SAS-A total score as the dependent variable. Although the sex by grade group interaction was not significant, there was a significant main effect for both sex and grade group. As shown in Table 4, girls had significantly higher SAS-A total scores than did boys, and students in the junior high group had significantly higher SAS-A total scores than did students in the senior high group. A $2 \times 2($ Sex $\times$ Grade Group) between-group multivariate analysis of variance (MANOVA) was calculated using the SAS-A subscale scores (i.e., FNE, SAD-New, and SAD-General) as the dependent variables. Although the sex by grade group interaction was not significant, there were significant multivariate effects for sex, $F(3$, $2929)=37.88, p<.0001$, Wilks's lambda $=.96$, and grade group, $F(3,2929)=11.28, p<.0001$, Wilks's lambda $=.98$. Univariate follow-up tests indicated a significant main effect for sex on both the FNE and the SAD-New subscales, with girls scoring significantly higher than boys on both. With regard to grade group differences, univariate follow-up tests indicated a significant main effect only on the FNE subscale, with students in the junior high group scoring significantly higher than those in the senior high group.

Table 3. Alpha Reliability Coefficients and Interscale Correlations for Social Anxiety Scale for Adolescents Subscales by Sex and Grade Group

\begin{tabular}{|c|c|c|c|c|c|}
\hline \multirow[b]{2}{*}{ Alpha/Correlation } & \multirow[b]{2}{*}{ Total Sample } & \multicolumn{2}{|c|}{ Junior High School } & \multicolumn{2}{|c|}{ Senior High School } \\
\hline & & Boys & Girls & Boys & Girls \\
\hline \multicolumn{6}{|l|}{ Alpha Coefficient } \\
\hline FNE & .89 & .89 & .91 & .87 & .88 \\
\hline SAD-New & .80 & .78 & .80 & .78 & .83 \\
\hline SAD-General & .70 & .68 & .69 & .73 & .75 \\
\hline \multicolumn{6}{|l|}{ Interscale Correlation } \\
\hline FNE and SAD-New & .60 & .60 & .56 & .63 & .64 \\
\hline FNE and SAD-General & .52 & .54 & .49 & .59 & .53 \\
\hline SAD-New and SAD-General & .59 & .58 & .59 & .62 & .60 \\
\hline
\end{tabular}

Note $:$ FNE = Fear of Negative Evaluation from Peers; SAD-New = Social Avoidance and Distress Specific to New Situations; SAD-General = Generalized Social Avoidance and Distress. All correlations are significant at $p<.001$.

Table 4. Means and Standard Deviations for Social Anxiety Scale for Adolescents by Sex and Grade Group

\begin{tabular}{|c|c|c|c|c|c|c|c|c|}
\hline \multirow[b]{2}{*}{ Group } & \multicolumn{2}{|c|}{ Total } & \multicolumn{2}{|c|}{ FNE } & \multicolumn{2}{|c|}{ SAD-New } & \multicolumn{2}{|c|}{ SAD-General } \\
\hline & $M$ & $S D$ & $M$ & $S D$ & $M$ & $S D$ & $M$ & $S D$ \\
\hline \multicolumn{9}{|l|}{ Sex } \\
\hline Boys & 41.84 & 12.39 & 18.69 & 6.72 & 12.91 & 4.03 & 10.26 & 3.69 \\
\hline Girls & 44.62 & 12.59 & 20.76 & 6.87 & 13.68 & 4.12 & 10.12 & 3.71 \\
\hline$F$ & $31.58 * *$ & & $62.92 * *$ & & $23.87 * *$ & & 1.55 & \\
\hline \multicolumn{9}{|l|}{ Grade Group } \\
\hline Junior High School & 43.92 & 12.90 & 20.28 & 7.22 & 13.77 & 4.14 & 10.29 & 3.73 \\
\hline Senior High School & 42.27 & 11.95 & 18.93 & 6.21 & 13.21 & 4.01 & 10.04 & 3.65 \\
\hline$F$ & $11.71^{*}$ & & $27.03 * *$ & & 1.05 & & 3.00 & \\
\hline \multicolumn{9}{|l|}{ Sex by Grade Group } \\
\hline \multicolumn{9}{|l|}{ Junior High School } \\
\hline Boys & 42.36 & 12.78 & 19.17 & 7.11 & 12.95 & 4.09 & 10.31 & 3.75 \\
\hline Girls & 45.38 & 12.85 & 21.31 & 7.17 & 13.77 & 4.15 & 10.26 & 3.72 \\
\hline \multicolumn{9}{|l|}{ Senior High School } \\
\hline Boys & 41.11 & 11.72 & 17.95 & 6.01 & 12.87 & 3.93 & 10.19 & 3.61 \\
\hline Girls & 43.40 & 12.07 & 19.88 & 6.26 & 13.54 & 4.07 & 9.89 & 3.69 \\
\hline$F$ & 0.59 & & 0.17 & & 0.26 & & 0.82 & \\
\hline
\end{tabular}

Note FNE = Fear of Negative Evaluation from Peers; SAD-New = Social Avoidance and Distress Specific to New Situations; SAD-General = Generalized Social Avoidance and Distress. All univariate tests for both sex and grade differences have $(1,2933)$ degrees of freedom. All univariate tests for minority students have $(1,2300)$ degrees of freedom.

${ }^{*} p<.001 . * * p<.0001$. 
SOCIAL ANXIETY SCALE FOR ADOLESCENTS

Table 5. Means and Standard Deviations for Revised Children's Manifest Anxiety Scale by Sex and Grade Group

\begin{tabular}{|c|c|c|c|c|c|c|c|c|}
\hline \multirow[b]{2}{*}{ Group } & \multicolumn{2}{|c|}{ Total } & \multicolumn{2}{|c|}{ PA } & \multicolumn{2}{|c|}{ WO } & \multicolumn{2}{|c|}{$\mathrm{SCC}$} \\
\hline & $M$ & $S D$ & $M$ & $S D$ & $M$ & $S D$ & $M$ & $S D$ \\
\hline \multicolumn{9}{|l|}{$\overline{\operatorname{Sex}}$} \\
\hline Boys & 7.64 & 5.85 & 2.76 & 2.17 & 2.84 & 2.66 & 2.01 & 1.80 \\
\hline Girls & 9.74 & 6.12 & 3.36 & 2.35 & 4.37 & 3.06 & 2.07 & 1.85 \\
\hline$F$ & $96.80 *$ & & $57.15^{*}$ & & $205.03 *$ & & 1.06 & \\
\hline \multicolumn{9}{|l|}{ Grade Group } \\
\hline Junior High School & 8.58 & 6.15 & 2.99 & 2.35 & 3.58 & 3.01 & 1.99 & 1.86 \\
\hline Senior High School & 8.93 & 5.64 & 3.18 & 2.18 & 3.70 & 2.91 & 2.11 & 1.76 \\
\hline$F$ & 2.67 & & 4.83 & & 1.47 & & 2.91 & \\
\hline \multirow{2}{*}{\multicolumn{9}{|c|}{$\begin{array}{l}\text { Sex by Grade Group } \\
\text { Junior High School }\end{array}$}} \\
\hline & & & & & & & & \\
\hline Boys & 7.64 & 5.84 & 2.77 & 2.30 & 2.84 & 2.71 & 1.97 & 1.86 \\
\hline Girls & 7.63 & 5.16 & 2.74 & 1.96 & 2.85 & 2.58 & 2.06 & 1.69 \\
\hline \multicolumn{9}{|l|}{ Senior High School } \\
\hline Boys & 9.45 & 6.30 & 3.20 & 2.37 & 4.27 & 3.11 & 2.01 & 1.86 \\
\hline Girls & 10.19 & 5.79 & 3.61 & 2.31 & 4.53 & 2.97 & 2.16 & 1.83 \\
\hline$F$ & 2.81 & & 6.42 & & 1.39 & & 0.18 & \\
\hline
\end{tabular}

Note $:$ PA = Physiological Arousal; WO = Worry/Oversensitivity; $\mathrm{SCC}=$ Social Concerns/Concentration. All univariate tests for both sex and grade differences have $(1,2933)$ degrees of freedom. All univariate tests for minority status differences have $(1,2300)$ degrees of freedom. $* p<.0001$.

Concurrent sex and grade differences on the RCMAS and CDI. To track concurrent sex and grade differences on the RCMAS and CDI, we calculated similar $2 \times 2(\operatorname{Sex} \times$ Grade Group $)$ analyses with scores on those measures as dependent variables. First, a $2 \times 2$ (Sex $\times$ Grade Group) ANOVA was conducted for RCMAS total scores. As shown in Table 5, only the main effect of sex was significant, with girls scoring higher than boys. A $2 \times 2$ (Sex $\times$ Grade Group) MANOVA was then conducted using the Physiological Arousal, Worry/Oversensitivity, and Social Concerns/Concentration subscales of the RCMAS as dependent variables. The multivariate effects for grade group and the sex by grade group interaction were not significant. The multivariate main effect for sex, however, was significant, $F(3,2391)=98.79, p<.0001$, Wilks's lambda $=.90$. As shown in Table 5, univariate follow-up tests indicated that girls scored higher than boys on the Physiological Arousal and Worry/ Oversensitivity subscales.

We also calculated a $2 \times 2($ Sex $\times$ Grade Group) ANOVA using the CDI total score as the dependent variable. As shown in Table 6, there was a significant main effect for both sex and grade group, with girls scoring significantly higher than boys and senior high students scoring significantly higher than junior high students. A $2 \times 2($ Sex $\times$ Grade Group) MANOVA was also conducted, using the subscales of the CDI as dependent variables. The multivariate effect for the sex by grade group interaction was not significant. However, the multivariate main effects for both sex, $F(5$, $2929)=47.11, p<.0001$, Wilks's lambda $=.92$, and grade group, $F(5,2929)=13.14, p<.0001$, Wilks's lambda $=.97$, were significant. The univariate followup tests indicated a significant sex effect for each of the
CDI subscales, with girls scoring higher than boys on the Negative Mood, Anhedonia, and Negative Self-Esteem subscales and boys scoring higher than girls on the Interpersonal Problems and Ineffectiveness subscales. With regard to the grade group main effect, univariate follow-up tests indicated significant differences on the Negative Mood, Ineffectiveness, Anhedonia, and Negative Self-Esteem subscale scores, with students in the senior high group scoring higher than those in the junior high group on each.

\section{Construct Validity}

Correlations among the SAS-A, RCMAS, and CDI. Pearson product-moment correlation coefficients were calculated between the SAS-A scales and both the RCMAS and CDI scales for the total sample (see Table 7). In general, the SAS-A total score and subscale scores were significantly and positively correlated with the RCMAS scales. Although generally not as strong, the SAS-A total score and subscale scores were also significantly and positively related to the CDI total score and the Negative Mood, Anhedonia, and Negative Self-Esteem subscale scores. The SAS-A total score and subscale scores were not significantly related to the Interpersonal Problems subscale of the $\mathrm{CDI}$, and only the SAS-A FNE subscale was related to the Ineffectiveness subscale of the CDI.

In addition to examining the overall pattern of correlations between the SAS-A and the RCMAS and CDI, we investigated differences in the strength of the correlations across the SAS-A subscale scores. We made these comparisons by using a $Z$ test for comparing nonindependent correlations proposed by Meng, Rosenthal, and Rubin (1990). Both the SAS-A total 
INDERBITZEN-NOLAN \& WALTERS

Table 6. Means and Standard Deviations for Children's Depression Inventory by Sex and Grade Group

\begin{tabular}{|c|c|c|c|c|c|c|c|c|c|c|c|c|}
\hline \multirow[b]{2}{*}{ Group } & \multicolumn{2}{|c|}{ Total } & \multicolumn{2}{|c|}{ NMD } & \multicolumn{2}{|c|}{ IP } & \multicolumn{2}{|c|}{ INF } & \multicolumn{2}{|c|}{ ANH } & \multicolumn{2}{|c|}{ NSE } \\
\hline & $M$ & $S D$ & $M$ & $S D$ & $M$ & $S D$ & $M$ & $S D$ & $M$ & $S D$ & $M$ & $S D$ \\
\hline \multicolumn{13}{|l|}{$\overline{\operatorname{Sex}}$} \\
\hline Boys & 8.15 & 6.97 & 1.54 & 1.81 & 0.90 & 1.22 & 1.81 & 1.78 & 2.63 & 2.42 & 1.26 & 1.61 \\
\hline Girls & 9.15 & 7.61 & 2.12 & 2.14 & 0.68 & 1.05 & 1.57 & 1.72 & 3.18 & 2.71 & 1.66 & 1.81 \\
\hline$F$ & $17.92 * *$ & & $68.67 * *$ & & $28.11^{* *}$ & & $10.20 *$ & & $38.82 * *$ & & $42.43^{* *}$ & \\
\hline \multicolumn{13}{|l|}{ Grade Group } \\
\hline Junior High School & 8.14 & 7.34 & 1.72 & 1.98 & 0.80 & 1.16 & 1.52 & 1.72 & 2.76 & 2.59 & 1.35 & 1.65 \\
\hline Senior High School & 9.49 & 7.22 & 2.03 & 2.05 & 0.77 & 1.12 & 1.93 & 1.78 & 3.16 & 2.57 & 1.66 & 1.82 \\
\hline$F$ & $23.82 * *$ & & $17.08^{* * *}$ & & 0.68 & & $37.76^{* *}$ & & $16.33^{* *}$ & & $23.53^{* *}$ & \\
\hline \multirow{2}{*}{\multicolumn{13}{|c|}{$\begin{array}{l}\text { Sex by Grade Group } \\
\text { Junior High School }\end{array}$}} \\
\hline & & & & & & & & & & & & \\
\hline Boys & 7.87 & 7.08 & 1.50 & 1.82 & 0.91 & 1.24 & 1.70 & 1.77 & 2.57 & 2.47 & 1.18 & 1.57 \\
\hline Girls & 8.60 & 6.79 & 1.61 & 1.81 & 0.89 & 1.19 & 1.98 & 1.79 & 2.73 & 2.34 & 1.39 & 1.67 \\
\hline \multicolumn{13}{|l|}{ Senior High School } \\
\hline Boys & 8.40 & 7.57 & 1.92 & 2.10 & 0.69 & 1.06 & 1.36 & 1.66 & 2.94 & 2.68 & 1.50 & 1.72 \\
\hline Girls & 10.36 & 7.51 & 2.43 & 2.18 & 0.65 & 1.03 & 1.89 & 1.77 & 3.57 & 2.72 & 1.92 & 1.92 \\
\hline$F$ & 5.02 & & 6.87 & & 0.05 & & 3.40 & & 6.11 & & 2.48 & \\
\hline
\end{tabular}

Note: NMD = Negative Mood; IP = Interpersonal Problems; INF = Ineffectiveness; ANH = Anhedonia; NSE = Negative Self-Esteem. All univariate tests for both sex and grade differences have $(1,2933)$ degress of freedom. All univariate tests for minority status differences have $(1$, 2300) degrees of freedom.

$* p<.001 . * * p<.0001$.

Table 7. Correlations Between the SAS-A and the RCMAS and CDI for the Total Sample

\begin{tabular}{lcccc}
\hline & \multicolumn{3}{c}{ SAS-A } \\
\cline { 2 - 5 } Measure/Subscale & Total & FNE & SAD-New & SAD-General \\
\hline RCMAS-Total Score & $.58_{\mathrm{a}}$ & $.58_{\mathrm{a}}$ & $.43_{\mathrm{b}}$ & $.38_{\mathrm{c}}$ \\
Physiological Arousal & $.35_{\mathrm{a}}$ & $.35_{\mathrm{a}}$ & $.25_{\mathrm{b}}$ & $.23_{\mathrm{b}}$ \\
Worry/Oversensitivity & $.60_{\mathrm{a}}$ & $.61_{\mathrm{a}}$ & $.47_{\mathrm{b}}$ & $.37_{\mathrm{c}}$ \\
Social Concerns/Concentration & $.49_{\mathrm{a}}$ & $.49_{\mathrm{a}}$ & $.33_{\mathrm{b}}$ & $.37_{\mathrm{b}}$ \\
CDI-Total Score & $.36_{\mathrm{a}}$ & $.37_{\mathrm{a}}$ & $.25_{\mathrm{b}}$ & $.26_{\mathrm{b}}$ \\
Negative Mood & $.35_{\mathrm{a}}$ & $.37_{\mathrm{a}}$ & $.25_{\mathrm{b}}$ & $.22_{\mathrm{b}}$ \\
Interpersonal Problems & $n s$ & $n s$ & $n s$ & $n s$ \\
Ineffectiveness & $n s_{\mathrm{b}}$ & $.20_{\mathrm{a}}$ & $n s_{\mathrm{b}}$ & $.26_{\mathrm{c}}$ \\
Anhedonia & $.37_{\mathrm{a}}$ & $.35_{\mathrm{a}, \mathrm{b}}$ & $.24_{\mathrm{b}}$ & $.30_{\mathrm{b}, \mathrm{c}}$ \\
Negative Self-Esteem & $.35_{\mathrm{a}}$ & $.37_{\mathrm{a}}$ & $.23_{\mathrm{b}}$ \\
\hline
\end{tabular}

Note : SAS-A = Social Anxiety Scale for Adolescents; RCMAS = Revised Children's Manifest Anxiety Scale; CDI = Children's Depression Inventory; FNE = Fear of Negative Evaluation from Peers; SAD-New = Social Avoidance and Distress Specific to New Situations; SAD-General = Generalized Social Avoidance and Distress. All correlations have 2932 degrees of freedom. Only correlations greater than or equal to .20 are listed. All correlations listed are significant at $p<.001$. Correlations within rows not sharing a common subscript differ significantly at $p<.001$.

and the FNE subscale evidenced significantly stronger, positive relations with the RCMAS (total and all three subscales) than did the SAD-New and the SAD-General subscales. Furthermore, the SAD-New subscale had a significantly stronger relation with the RCMAS total and Worry/Oversensitivity subscale than did the SAD-General subscale, whereas there was no significant difference between the correlations for the SADNew and SAD-General subscales and the RCMAS Physiological Arousal and Social Concerns/Concentration subscales.

A similar pattern of differences across the SAS-A scales was found with regard to the CDI. Both the SASA total and the FNE subscale evidenced significantly stronger, positive relations with the CDI total score and Negative Mood, Anhedonia, and Negative Self-Esteem subscales than did the SAD-New subscale. Additionally, both the SAS-A total and the FNE subscale had significantly stronger positive relations with the CDI total and Negative Mood and Negative Self-Esteem subscales than did the SAD-General subscale. Finally, the FNE subscale was the only SAS-A scale to significantly correlate with the Ineffectiveness subscale of the CDI.

\section{Differences in correlations across subsamples.}

Differences in the pattern and strength of the correlations between the SAS-A and the RCMAS and CDI across sex and grade groups were also examined (see Table 8). Correlations between specific SAS-A scales (e.g., FNE) and specific scales of the RCMAS and CDI 
were compared across sex and grade groups. We made these comparisons by using the $Z$ test for independent correlations, based on Fisher's Z-transformations (Snedecor \& Cochran, 1989). When these comparisons were made, only two sex differences emerged. There was a significant, positive relation between the CDI Ineffectiveness subscale and both the SAS-A total and FNE subscale for girls, whereas the scales were not significantly related for boys.

Significant grade group differences emerged for the relation between the SAS-A and both the RCMAS and $\mathrm{CDI}$, with all differences showing a stronger, positive relation for junior high students than senior high students. When we examined the relation between the SAS-A and the RCMAS, there was a stronger, positive relation between the Physiological Arousal subscale of the RCMAS and the SAS-A total, SAD-New, and SAD-General subscales of the SAS-A for junior high students compared with senior high students. In fact, for both the SAD-New and SAD-General subscales, the relation with the Physiological Arousal subscale was nonsignificant for senior high students. Additionally, junior high students evidenced a stronger, positive relation between the SAS-A total score and the RCMAS total score than did senior high students.

When examining the grade group differences for the relation between the SAS-A and the CDI, we found differences for each of the SAS-A scales. Junior high school students evidenced a statistically significant stronger, positive relation between SAS-A total scores and CDI total score, and CDI Ineffectiveness and Anhedonia subscales, than did students in senior high. In fact, the relation between the SAS-A total score and the Ineffectiveness subscale of the CDI was not significant for senior high students but was for the junior high students. For the FNE subscale, the junior high students evidenced a significantly stronger positive relation with the CDI Ineffectiveness, Anhedonia, and Negative Self-Esteem subscale scores than did senior high students. Again, the relation between the FNE subscale and the Ineffectiveness subscale of the CDI was not significant for senior high students. Junior high students also had significant positive relations between the SAD-New subscale and the CDI total score as well as between the SAD-General subscale and the CDI Negative Mood subscale. These relations, however, were nonsignificant for senior high students.

\section{Discussion}

Results of this study provide evidence of a relatively clean factor structure and internal consistencies for the subscales of the SAS-A, with additional evidence that the subscales represent interrelated but distinct subconstructs of social anxiety. These data also provide

Table 8. Correlations Between SAS-A Scales and Scales of the RCMAS and CDI by Grade Group and Sex

\begin{tabular}{|c|c|c|c|c|c|c|c|c|c|c|}
\hline & \multicolumn{4}{|c|}{ RCMAS Scale } & \multicolumn{6}{|c|}{ CDI Scale } \\
\hline & TOT & PA & Wo & SCC & TOT & NMD & IP & INF & ANH & NSE \\
\hline \multicolumn{11}{|l|}{ SAS-A Total } \\
\hline Boys & .53 & .33 & .56 & .46 & .32 & .30 & - & $-\mathrm{a}$ & .35 & .31 \\
\hline Girls & .59 & .34 & .62 & .51 & .39 & .37 & - & $.20 \mathrm{a}$ & .37 & .36 \\
\hline Junior High School & $.61_{\mathrm{b}}$ & $.41_{\mathrm{b}}$ & .63 & .52 & $.41_{\mathrm{b}}$ & .39 & - & $.23_{\mathrm{b}}$ & $.43_{b}$ & .40 \\
\hline Senior High School & $.51_{\mathrm{b}}$ & $.24_{b}$ & .55 & .44 & $.29 \mathrm{~b}$ & .29 & - & $-_{\mathrm{b}}$ & $.29 \mathrm{~b}$ & .30 \\
\hline \multicolumn{11}{|l|}{ FNE } \\
\hline Boys & .53 & .33 & .55 & .46 & .32 & .32 & - & $-\mathrm{a}$ & .24 & .22 \\
\hline Girls & .59 & .34 & .63 & .52 & .41 & .40 & - & $.25_{\mathrm{a}}^{\mathrm{a}}$ & .36 & .40 \\
\hline Junior High School & .62 & .41 & .64 & .53 & .43 & .43 & - & $.25_{\mathrm{b}}$ & $.41_{\mathrm{a}}$ & $.42_{\mathrm{a}}$ \\
\hline Senior High School & .51 & .25 & .56 & .43 & .30 & .31 & - & $-\mathrm{b}$ & $.26_{\mathrm{a}}$ & $.33_{\mathrm{a}}$ \\
\hline \multicolumn{11}{|l|}{ SAD-New } \\
\hline Boys & .39 & .24 & .44 & .30 & .21 & .20 & - & - & .24 & .22 \\
\hline Girls & .45 & .25 & .49 & .36 & .28 & .28 & - & - & .27 & .25 \\
\hline Junior High School & .46 & $.31_{\mathrm{b}}$ & .49 & .36 & $.30_{\mathrm{b}}$ & .29 & - & - & .31 & .29 \\
\hline Senior High School & .37 & $-_{\mathrm{b}}$ & .44 & .29 & $-\mathrm{b}$ & .20 & - & - & - & - \\
\hline \multicolumn{11}{|l|}{ SAD-General } \\
\hline Boys & .37 & .23 & .37 & .36 & .26 & .20 & - & - & .32 & .25 \\
\hline Girls & .41 & .24 & .41 & .38 & .26 & .23 & - & - & .28 & .23 \\
\hline Junior High School & .41 & $.27 \mathrm{~b}$ & .40 & .39 & .29 & $.24 \mathrm{~b}$ & - & - & .32 & .26 \\
\hline Senior High School & .34 & $-\mathrm{b}$ & .34 & .34 & .23 & $-\mathrm{b}$ & - & - & .26 & .20 \\
\hline
\end{tabular}

Note: SAS-A = Social Anxiety Scale for Adolescents; RCMAS = Revised Children's Manifest Anxiety Scale; CDI = Children's Depression Inventory; TOT $=$ Total Score; $\mathrm{PA}=$ Physiological Arousal; $\mathrm{WO}=$ Worry $/$ Oversensitivity; $\mathrm{SCC}=$ Social Concerns $/$ Concentration; TOT $=$ Total Score; NMD = Negative Mood; IP = Interpersonal Problems; INF = Ineffectiveness; ANH = Anhedonia; NSE = Negative Self Esteem; FNE = Fear of Negative Evaluation from Peers; SAD-New = Social Avoidance and Distress Specific to New Situations; SAD-General = Generalized Social Avoidance and Distress. Correlations have 1427, 1503, 1791, and 1139 degrees of freedom for boys, girls, junior high school, and senior high school, respectively. Only correlations greater than or equal to .20 are listed. All correlations listed are significant at $p<.001$. Vertically adjacent correlations sharing the ${ }_{\mathrm{a}}$ or ${ }_{\mathrm{b}}$ subscripts indicate sex or grade level differences, respectively (significant at $p<.001$ ). 
the most comprehensive set of normative data, subdivided by both sex and grade group, yet presented for the SAS-A. Finally, we provided additional construct validity for the SAS-A by examining its relations with general or unspecified anxiety (i.e., RCMAS) and depressive symptomatology (i.e., CDI).

\section{Psychometric Properties}

With regard to the psychometric analyses of the SAS-A, this study produced a factor structure nearly identical to that obtained in previous studies with the SAS-A (La Greca \& Lopez, 1998) and with the SASCR (La Greca \& Stone, 1993). This data also replicated previous findings for the three subscales of the SAS-A in terms of overall model fit, internal consistencies, and intercorrelations among the subscales. Furthermore, these findings were relatively consistent across sex and grade group subsamples, providing evidence of the generalizability of the three-factor structure of the SAS-A.

\section{Sex and Grade Group Differences}

Also consistent with previous research using both child and adolescent populations (La Greca, 1998), results from this study indicated that girls reported greater social anxiety than boys. Girls in this study had higher scores on the SAS-A total, the FNE subscale, and the SAD-New subscale than did boys. Given that past research has found that adolescent girls, in comparison with boys, are overconcerned about their social competence (Kashani, Orvaschel, Rosenberg, \& Reid, 1989) and place higher importance on interpersonal relationships (Maccoby, 1990), it is not surprising that girls report higher levels of social anxiety.

Although previous studies using adolescent populations have not found significant age differences (La Greca, 1998), results from this study indicated that adolescents in junior high school reported greater levels of social anxiety than did those in senior high school. This age difference is consistent with literature suggesting that the developmental period of early adolescence is marked by increased self-consciousness and sensitivity to self-presentational concerns (Buss, 1986; Elkind, 1980). In addition, early to midadolescence is typically the time during which the physical changes associated with puberty occur, individuals experience significant transitions in the school environment, peer relations take on a new importance, and youths begin to exercise self-determination and autonomy with regard to friendship selections. Thus, it is understandable that adolescents in junior high grades reported experiencing greater social anxiety than those in senior high.

Additionally, early to midadolescence is typically associated with the onset of formal operational thought that likely results in an awareness of discrepancies be- tween the perceptions of oneself by one's peers and one's self-perceptions. Thus, age differences in the experience of social anxiety may lie predominantly in the cognitive realm (i.e., negative self-evaluation and fear of negative evaluation by others) as opposed to the behavioral realm (i.e., social avoidance). Such a supposition may account for the finding that when differences across subscales were examined, grade group differences emerged for the FNE subscale but not the two SAD subscales.

Although previous research using adolescents has not found age differences, these results suggesting a decline in social anxiety in the high school grades are consistent with research presented by La Greca (1998). When we compare scores on the SASC-R and SAS-A across samples from different studies, it appears that social anxiety scores for elementary school students are also higher than those for high school students with regard to both the total and FNE scores (La Greca, 1998).

In addition to examining sex and grade group differences on the SAS-A, we examined these same between-group differences with regard to RCMAS and CDI scores. Findings from this study indicating that girls reported more anxiety and depressive symptoms than boys (i.e., RCMAS total and CDI total scores) are also consistent with past research. For example, Lewinsohn, Hops, Roberts, Seeley, and Andrews (1993), using a nonclinical adolescent population and a clinical interview, found that girls were more likely to be diagnosed with a depressive or anxiety disorder than were boys. With regard to self-report measures, Bernstein and colleagues (i.e., Bernstein, Crosby, Perwien, \& Borchardt, 1996; Bernstein, Garfinkel, \& Hoberman, 1989) found that adolescent girls scored higher on both the RCMAS and the CDI than did boys.

Although there were no grade group differences with regard to RCMAS scores, students in senior high scored higher than those in junior high school on all of the CDI scores except for the Interpersonal Problems subscale. This age difference with regard to self-reported depressive symptomatology is also consistent with past research. For example, Angold and Rutter (1992) found that the rates of depressive disorders increased with age regardless of sex, and Craighead, Smucker, Craighead, and Ilardi (1998) found that CDI total scores as well as several different factor scores increased with age.

\section{Construct Validity}

With regard to construct validity, this data replicated previous research that found a moderate relation between total scores on the RCMAS and total scores on the SASC ( $r=.57$; La Greca et al., 1988). In addition, comparable with previous research with both the SASC (La Greca et al., 1988) and the SASC-R (Inderbitzen \& Hope, 1995), results indicated that the positive relation 
with the RCMAS was somewhat stronger for the FNE subscale than for the SAD-New and SAD-General subscales and that this pattern of associations held for each of the subscales of the RCMAS.

It is possible that the stronger association between the RCMAS and the FNE subscale, in comparison with the SAD-General and SAD-New subscales, is attributable to common content. That is, items in the FNE subscale appear to be more affective and cognitive in nature (e.g., "I worry," "I feel"), whereas items in the SAD-General and SAD-New subscales are more behavioral (e.g., "I get nervous," "I'm quiet," "It's hard for me to $1 / 4$ "). The items on the RCMAS also appear to be more affective and cognitive than behavioral (e.g., "I worry," "I feel"). Thus, the stronger relation may be partly attributable to greater overlap in item content between the RCMAS and the FNE. In addition, the items on the FNE reflect social evaluative anxiety, whereas those on the two SAD subscales reflect distress and avoidance. Therefore, it may be that the stronger relation between the RCMAS and the FNE is attributable to the evaluative aspects common in both social and more generalized anxiety.

When we examined associations between the SASA and RCMAS across sex, the strength of the relations was equivalent for boys and girls. When the associations were examined by grade group, however, several differences emerged, indicating stronger associations for junior high school students, especially with regard to relations between the Physiological Arousal subscale and the SAS-A. Such grade group differences may be explained by better ability to discriminate among anxious symptomatology by older students as a result of more advanced cognitive skills. That is, perhaps when younger students feel physiologically aroused, these sensations generalize to many situations so that they report greater anxious symptomatology overall. Older students, however, may be better able to recognize the specificity of their physiological arousal so that only specific situations or symptoms are endorsed.

We also examined the construct validity of the SAS-A by investigating the relation between the SASA and depressive symptomatology, as measured by the CDI. The associations between the SAS-A and the CDI were generally weaker than for the RCMAS, providing evidence for discriminant validity. Also, the SAS-A was only meaningfully related to the more affectively oriented subscales of the CDI: Negative Mood, Anhedonia, and Negative Self-Esteem. The SAS-A was essentially unrelated to Ineffectiveness and Interpersonal Problems. Although intuitively one would hypothesize that social anxiety would be related to the Interpersonal Problems and Ineffectiveness subscales of the CDI, on closer examination of the items that comprise these two CDI subscales, a lack of relation is understandable. The Interpersonal Problems subscale of the CDI appears to assess externalizing problems, whereas the Ineffectiveness subscale appears to assess academic achievement and motivation. Given that previous research has not shown a significant relation between social anxiety and conduct problems or achievement and motivation, it is not surprising that such relations were not found in this study.

Similar to the patterns of relations found between the SAS-A and the RCMAS, the FNE subscale of the SAS-A was correlated more strongly with the CDI (total and subscale scores) than were the two SAD subscales. Once again, it is likely that the stronger associations with the FNE are attributable to the greater affective content of these items in comparison with those comprising the two SAD subscales.

Although the Ineffectiveness subscale of the CDI was essentially unrelated to the SAS-A for the total sample, it was positively related to SAS-A total scores and FNE subscale scores for girls. It is possible that this sex difference can be attributed to differences in the interpretation or representation of items on the Ineffectiveness subscale. For example, boys may respond to several of the items (e.g., "I do many things wrong"; "My schoolwork is not as good as before"; "I can never be as good as other kids") as a reflection of conduct problems, whereas girls may respond to the same items as a representation of their general feelings of selfworth. This hypothesis is consistent with findings from La Greca and Lopez (1998) indicating that linkages between social anxiety and other aspects of social functioning are stronger for adolescent girls than boys.

Finally, there were numerous grade group differences with regard to the relations between the CDI and the SAS-A, all indicating stronger associations for students in junior high compared with those in senior high school. Because of the importance of peer relations during early adolescence and the unique social pressures during this developmental period, it is likely that these youths experience some depressive symptomatology linked to their social anxiety. On the other hand, social anxiety may not be a new experience for youths in senior high. As such, these youths may have learned successful coping techniques (e.g., having several close friends and not being concerned with being accepted into a social clique) so that they do not experience as much depressive symptomatology linked to their social anxiety. However, such a supposition is purely speculative, and future research should explore this grade group difference more systematically.

\section{Future Directions}

Although this study provides further psychometric and normative data for the SAS-A, it is not without limitations. Although the sample size is large, it is relatively restricted with regard to ethnic and racial heterogeneity. Thus, it will be important for future research to collect 
normative data from a more racially and ethnically diverse sample so that ethnic differences can be investigated more comprehensively. Furthermore, the sample in this study was selected from only one geographic location. Thus, although the results from this study are highly similar to those collected by La Greca and Lopez (1998), additional research should be done using samples from other geographic locations and samples that include urban, suburban, and rural areas.

Results from this study suggest that the most problematic time for youth experiencing social anxiety is during junior high and that girls may be more at risk than boys. Given that this sample was drawn from a community population, however, it will be important for researchers to determine whether such age and sex differences exist in clinical populations. Furthermore, additional research examining the clinical significance of such findings is required.

Finally, although these findings provide a useful contribution to the construct validity of the SAS-A, additional work is needed. The validity of the SAS-A needs to be investigated using other measurement methodologies (i.e., diagnostic interviews, behavioral observations) and with additional clinical samples. Additionally, the utility of the SAS-A for diagnostic and treatment purposes should be investigated. Nevertheless, these results, in conjunction with past studies investigating the psychometric properties of the SAS-A (i.e., Ginsburg et al., 1998; La Greca \& Lopez, 1998;), suggest that the SAS-A is a psychometrically sound and useful instrument for assessing social anxiety in adolescents.

\section{References}

Angold, A., \& Rutter, M. (1992). Effects of age and pubertal status on depression in a large clinical sample. Development and Psychopathology, 4, 5-28.

Ballenger, J. C., Davidson, J. R. T., Lecrubier, Y., Nutt, D. J., Bobes, J., Beidel, D. C., Ono, Y., \& Westenberg, H. G. M. (1998). Consensus statement on social anxiety disorder from the International Consensus Group on Depression and Anxiety. Journal of Clinical Psychiatry, 59, 54-60.

Beidel, D. C., \& Randall, J. (1994). Social phobia. In T. H. Ollendick, N. J. King, \& W. Yule (Eds.), International handbook of phobic and anxiety disorders in children and adolescents (pp. 111129). New York: Plenum.

Benjamin, R. S., Costello, E. J., \& Warren, M. (1990). Anxiety disorders in a pediatric sample. Journal of Anxiety Disorders, 4, $293-$ 316.

Bernstein, G. A., Crosby, R. D., Perwien, A. R., \& Borchardt, C. M. (1996). Anxiety rating for children-revised: Reliability and validity. Journal of Anxiety Disorders, 10, 97-114.

Bernstein, G. A., Garfinkel, B. D., \& Hoberman, H. A. (1989). Selfreported anxiety in adolescents. American Journal of Psychiatry, 146, 384-386.

Buss, A. H. (1986). A theory of shyness. In W. H. Jones, J. M. Cheek, \& S. R. Biggs (Eds.), Shyness: Perspectives on research and treatment (pp. 39-46). New York: Plenum.
Carlson, G. A., \& Cantwell, D. P. (1979). A survey of depressive symptoms in a child and adolescent psychiatric population. Journal of the American Academy of Child Psychiatry, 18, 587599.

Clark, D. B. (1993, March). Assessment of social anxiety in adolescent alcohol abusers. Paper presented at the Anxiety Disorders Association of America Annual Convention, Charleston, SC.

Craighead, W. E., Smucker, M. R., Craighead, L. W., \& Ilardi, S. S. (1998). Factor analysis of the Children's Depression Inventory in a community sample. Psychological Assessment, 10, 156165 .

Davidson, J. R. T., Hughes, D. L., George, L. K., \& Blazer, D. G. (1993). The epidemiology of social phobia: Findings from the Duke Epidemiological Catchment Area Study. Psychological Medicine, 23, 709-718.

Elkind, D. (1980). Strategic interactions in early adolescence. In J. Adelson (Ed.), Handbook of adolescent psychology (pp. 432444). New York: Wiley.

Francis, G., Last, C. G., \& Strauss, C. C. (1992). Avoidant personality disorder and social phobia in children and adolescents. Journal of the American Academy of Child and Adolescent Psychiatry, 31, 1086-1089.

Ginsberg, G., La Greca, A. M., \& Silverman, W. S. (1997, November). Social anxiety in adolescents with anxiety disorders: Utility of the Social Anxiety Scale for Adolescents. Poster presented at the Annual Convention of the Association for the Advancement of Behavior Therapy, Miami Beach, FL.

Ginsberg, G., La Greca, A. M., \& Silverman, W. S. (1998). Social anxiety in children with anxiety disorders: Relation with social and emotional functioning. Journal of Abnormal Child Psychology, 26, 175-185.

Inderbitzen, H. M., \& Hope, D. A. (1995). Relationship among adolescent reports of social anxiety, anxiety, and depressive symptoms. Journal of Anxiety Disorders, 9, 385-396.

Inderbitzen, H. M., Walters, K. S., \& Bukowski, A. L. (1997). The role of social anxiety in adolescent peer relations: Differences among sociometric status groups and rejected subgroups. Journal of Clinical Child Psychology, 26, 338-348.

Kashani, J. H., Orvaschel, H., Rosenberg, T. K, \& Reid, J. C. (1989). Psychopathology in a community sample of children and adolescents: A developmental perspective. American Academy of Child and Adolescent Psychiatry, 28, 701-706.

Kovacs, M., \& Beck, A. T. (1977). An empirical-clinical approach toward a definition of childhood depression. In J. G. Schulterbrandt \& A. Raskin (Eds.), Depression in childhood: Diagnosis, treatment, and conceptual models (pp. 1-25). New York: Raven.

La Greca, A. (1998). Manual for the Social Anxiety Scales for Children and Adolescents. Miami, FL: University of Miami.

La Greca, A. M., Dandes, S. K., Wick, P., Shaw, K., \& Stone, W. L. (1988). Development of the Social Anxiety Scale for Children: Reliability and concurrent validity. Journal of Clinical Child Psychology, 17, 84-91.

La Greca, A. M., \& Lopez, N. (1998). Social anxiety among adolescents: Linkages with peer relations and friendships. Journal of Clinical Child Psychology, 26, 83-94.

La Greca, A. M., \& Stone, W. L. (1993). Social Anxiety Scale for Children-Revised: Factor structure and concurrent validity. Journal of Clinical Child Psychology, 22, 17-27.

Last, C. G., Perrin, S., Hersen, M., \& Kazdin, A. E. (1992). DSM-III$\mathrm{R}$ anxiety disorders in children: Sociodemographic and clinical characteristics. Journal of the American Academy of Child and Adolescent Psychiatry, 31, 1070-1076.

Lewinsohn, P. M., Hops, H., Roberts, R. E., Seeley, J. R., \& Andrews, J. A. (1993). Adolescent psychopathology: I. Prevalence and incidence of depression and other DSM-III-R Disorders in 


\section{SOCIAL ANXIETY SCALE FOR ADOLESCENTS}

high school students. Journal of Abnormal Psychology, 102, 133-144.

Maccoby, E. E. (1990). Gender and relationship: A developmental account. American Psychologist, 45, 513-520.

Meng, X. -L., Rosenthal, R., \& Rubin, D. B. (1990). Comparing correlated correlation coefficients. Manuscript submitted for publication.

Reiss, A. J. (1961). Occupations and social status. New York: The Free Press of Glencoe.

Reynolds, C. R., \& Richmond, B. O. (1978). What I think I feel: A revised measure of children's manifest anxiety. Journal of Abnormal Child Psychology, 6, 271-280.

Reynolds, C. R., \& Richmond B. O. (1985). Revised Children's Manifest Anxiety Scale (RCMAS)-manual. Los Angeles: Western Psychological Services.

Saylor, C. F., Finch, A. J., Spirito, A., \& Bennett, B. (1984). The Children's Depression Inventory: A systematic evaluation of psychometric properties. Journal of Consulting and Clinical Psychology, 52, 955-967.

Snedecor, G. W., \& Cochran, W. G. (1989). Statistical methods. Ames: Iowa State University Press.
Strauss, C. C., \& Francis, G. (1989). Phobic disorders. In C. G. Last \& M. Hersen (Eds.), Handbook of child psychiatric diagnosis (pp. 170-190). New York: Wiley.

Strauss, C. C., \& Last, C. G (1993). Social and simple phobias in children. Journal of Anxiety Disorders, 7, 141-152.

Verhulst, F. C., van der Ende, J., Ferdinand, R. F., \& Kasius, M. C. (1997). The prevalence of DSM-III-R diagnoses in a national sample of Dutch adolescents. Archives of General Psychiatry, 54, 329-336.

Vernberg, E. M., Abwender, D. A., Ewell, K. K., \& Beery, S. H. (1992). Social anxiety and peer relationships in early adolescence: A prospective analysis. Journal of Clinical Child Psychology, 21, 189-196.

Watson, D., \& Friend, R. (1969). Measurement of social-evaluative anxiety. Journal of Consulting and Clinical Psychology, 33, 448-457.

Manuscript received July 23, 1999

Final revision received April 5, 2000 